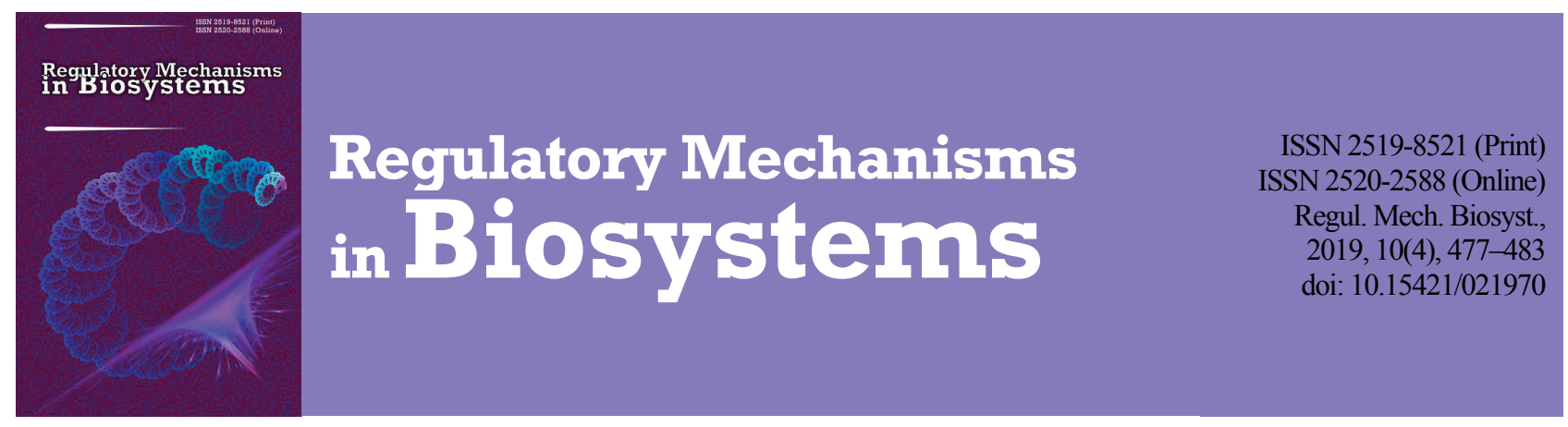

\title{
Evaluation of commercial methods to separate nucleic acids from intestinal tissues of pigs for diagnosis of porcine epidemic diarrhea
}

\author{
D. M. Masiuk*, V. S. Nedzvetsky*, **, A. V. Kokariev*, O. V. Danchuk***, T. O. Vasilenko*, O. M. Yefimova* \\ *Dnipro State Agrarian and Economic University, Dnipro, Ukraine \\ **Bingöl University, Bingöl, Turkey \\ ***Odessa State Agricultural University, Odessa, Ukraine
}

Article info

Received 25.09.2019

Received in revised form 20.10.2019

Accepted 21.10.2019

Dnipro State Agrarian and Economic University, Sergiy Efremov st., 25, Dnipro, 49600, Ukraine. Tel.: + 38-050-636-62-37. E-mail:dimasiuk@gmail.com

Bingöl University, Selahaddin-i Eyyubi Mah. Üniversite Cad., 1 , Bingöl, 12000, Turkey. Tel.: +90-505-97-51-282. E-mail:

nedzvetskyvictor@gmail.com

Odessa State Agricultural University, Panteleymonovskaya st., 13, Odessa, 65012, Ukraine. Tel.: +38-067-767-91-33. E-mail:olexdan@ukr.net

\begin{abstract}
Masiuk, D. M., Nedzvetsky, V.S., Kokariev, A. V., Danchuk, O. V., Vasilenko, T. O., \& Yefimova, O. M. (2019). Evaluation of commercial methods to separate nucleic acids from intestinal tissues of pigs for diagnosis of porcine epidemic diarrhea. Regulatory Mechanisms in Biosystems, 10(4), 477-483. doi:10.15421/021970

The article presents the results of evaluating commercial methods for extracting nucleic acids from pig intestinal tissues for the diagnosis of PED. The study was based on samples of small intestine tissues and faeces from 3-5 day old pigs which died from PED. Nucleic acid extraction was performed using commercial kits with different nucleic acid separation strategies based on: silicon-sorbent; silicate membrane fixed in a microcentrifuge column and magnetic balls. The studies were conducted in two stages. The first was a comparison of the results of the amplification of the obtained nucleic acid extracts from the homogenate of the intestines of piglets by using the above-mentioned commercial kits for the extraction of nucleic acids. For this purpose, samples of homogenate were used which in weight corresponded to the guideline for the application of the test kits. The second step was directed to determining the efficiency of extraction of DNA and RNA from homogenate samples with a weight of 10, 50, 100 and $200 \mathrm{mg}$. Determination of the optimal methodological strategy of nucleic acid extraction for the diagnosis of porcine epidemic diarrhea by PCR has been investigated. The results of the PCR studies of RNA of the PED virus and a unique pig DNA fragment indicate that the extraction of nucleic acids by commercial kits has different levels of efficiency and depends on different factors. According to the research, it was found that the most important of them are the adsorption capacity of the solid-phase sorbent, its configuration and nature, which binds RNA and DNA molecules, the type of sample from which extraction takes place, its volume, or the tissue mass used for extraction. Based on the obtained results, it has been found that the most effective PED virus RNA extraction is by "ArtBioTech", "Bio Extract Column", and "Viral DNA/RNA Extraction Kit", and pig genomic DNA extraction by the "ArtBioTech" and "Viral DNA / RNA extraction Kit".
\end{abstract}

Keywords: DNA/RNA extraction methods; PEDv; intestinal tissue; faeces; commercial kits; PCR.

\section{Introduction}

Nucleic acid extraction is the process of separating different forms of DNA and RNA from other biological macromolecules using a specific sequence of biochemical and biophysical methods (Busa et al., 2016). The first protocol for the isolation and purification of nucleic acids was developed by Johannes Friedrich Miescher in 1869 (Greenly et al., 2015). The process of nucleic acid extraction is a fundamentally important step in modern molecular genetic studies, such as polymerase chain reaction (PCR), sequencing, restriction analysis, molecular hybridization, etc (Ali et al., 2017; Akshara, 2018). For testing, all these methods require a solution of nucleic acids with a high degree of purification and a minimal level of degradation of their molecules (Hardy et al., 2017).

Intracellular nucleic acids are divided into genomic (chromosomal) and plasmid DNA as well as separate types of RNA. In general, despite some differences in the composition of RNA and DNA (the presence of uracil or thymine) and the unique three-dimensional conformation of these linear biopolymers, the basic physicochemical properties of nucleic acids are similar. Current methods of nucleic acid extraction have been successfully used, with only minor modifications, both for DNA and RNA isolation. An important difference between DNA and RNA extraction methods is that RNA has a higher lability and sensitivity to a wide range of RNA, which increases the risk of degradation of the ribonucleic acid molecule (Chacon-Cortes, 2014).
The quality of nucleic acid extraction is one of the important steps for molecular genetic studies, in particular polymerase chain reaction (PCR). It directly affects the kinetics, which depend on the concentration of the extracted nucleic acids, their degree of destruction and purification of nucleic acid solution from PCR enzyme inhibitors (Chacon-Cortes et al., 2014; Cui et al., 2015; El-Maklizi et al., 2015). PCR enzyme inhibitors are quite important in the extraction of genetic material from samples, which are rich in low molecular weight substances that have inhibitory properties against enzymes, as well as enzymes that increase the destruction of nucleic acids - DNA and RNA (Busa et al., 2016). The most common material is faecal or intestinal specimens, which in most cases are used as an object of research for the indication and identification of the etiology of gastrointestinal infections by PCR (Choi et al., 2014; Carvajal et al., 2015). For today, there is a wide range of nucleic acid extraction methods, among which the most effective and consequently the most common are solidphase methods. These include modern variants of methods of extracting nucleic acids on magnetic balls, silicate membrane, silicon sorbent, etc. (Fong et al., 2015; Busin et al., 2016).

One of the most common diseases in pigs in Western European countries and since 2014 in Ukraine is porcine epidemic diarrhea (PED) which leads to significant economic losses (Cochrane et al., 2015; Gerber et al., 2016; Yonghyan et al., 2017; Wanitchang et al., 2019). PED is caused by the RNA genomic coronavirus and is accompanied by diarrhea in pigs of different sex-age groups and causes high mortality (up to 100\%) 
among animals in the first week of life (Cochrane et al., 2015; BjustromKraft et al., 2016; Sun et al., 2018; Yuan et al., 2019). The PCR method is most effective for the diagnosis of PED in industrial pig production (Tun et al., 2016; Kao et al., 2018; Masiuk et al., 2018; Hou et al., 2019). This method allows the detection of PED virus RNA even with minimal concentration of it in the test material. Taking into account the biological characteristics of the pathogen of $\mathrm{PED}$, as a rule, the diagnostics procedure requires the analysis of intestinal tissue containing undigested residues or faeces. Intestinal tissue samples are known to contain a large number of PCR-inhibitors substances. Therefore, the choice of a methodological strategy for the extraction of nucleic acids from intestinal tissue and faeces, which extracts DNA and RNA in sufficient quality, and allows one to effectively get rid of PCR inhibitors is an extremely important issue for the diagnosis of PED. The purpose of the study is to determine the optimal methodological strategy of nucleic acid extraction for the diagnosis of porcine epidemic diarrhea by PCR.

\section{Materials and methods}

The study was conducted in accordance with the requirements of the European Convention on the Protection of Vertebrate Animals (Strasbourg, 1986) and the Law of Ukraine "On the protection of animals from abuse" (2006), which was confirmed by the conclusion of the Bioethics Commission of the Dnipro State Agrarian and Economic University. The study was performed in the laboratory of immunochemical and molecular genetic analysis of the Scientific Research Centre of Biosafety and Environmental Control of the Agro-industrial Complex of Dnipro State Agrarian and Economic University. The study was carried out using the samples of small intestine tissues and faeces from 3-5 days old piglets, whose cause of death was PED. Nucleic acid extraction was performed using commercial kits with different nucleic acid separation strategies based on a: silicon-sorbent; silicate membrane fixed into a microcentrifuge column and magnetic balls.

Kit 1 - "S-Sorb" (Russia). This set of reagents is intended for the extraction of nucleic acids by precipitation with silicon sorbent.

Kit 2 - "FBioNucleo" (Russia). The reagent set is intended for the extraction of nucleic acids by depositing them on a silicate membrane fixed to a microcentrifuge column.

Kit 3 - "ArtBioTeh" (Belarus). The reagent kit is intended for the extraction of nucleic acids by depositing them on a silicate membrane fixed to a microcentrifuge column.

Kit 4 - "BioExtract Column" (France). The reagent kit is intended for the extraction of nucleic acids by depositing them on a silicate membrane fixed into a microcentrifuge column.

Kit 5 - "Viral DNA/RNA Extraction Kit" (Taiwan). The reagent kit is designed for the extraction of nucleic acids by magnetic balls. The method is based on the automated extraction of nucleic acids using the device "ZiXpress-32".

All studies were carried out in two stages. The first step was a comparison of the results of the amplification of the obtained nucleic acid extracts from the homogenate of the intestines of piglets by using the abovementioned commercial kits for the extraction of nucleic acids. For this purpose, samples of homogenate were used which in weight corresponded to the guideline for the application of the test kits. For Kit $1-4$ $100 \mathrm{mg}$, for Kit 5-40 mg. The second step was to determine the efficiency of extraction of DNA and RNA from homogenate samples with a weight of 10, 50, 100 and $200 \mathrm{mg}$ using the same commercial kits. The elution of nucleic acids of each sample was carried out in $100 \mu \mathrm{L}$ of elution solution. Extraction of nucleic acids from the test samples was performed in each kit of five repetitions.

The quality of extraction was determined for amplification by using RT-PCR-RT kits for the diagnosis of PED from two manufacturers: "EXOone PEDV" (Spain) and "PED RNA Detection Kit" (Russia). Reverse transcription, cDNA amplification, and fluorescence detection were performed according to methodological guidelines for the respective test systems on the CFX-96 "REAL TIME" amplifier (USA). Amplification results are given in Threshold cycle $(\mathrm{Ct})$ values. The cDNA replication process of the PED virus was evaluated by fluorescence at a wavelength of $520 \mathrm{~nm}$ for the "EXOone PEDV" test system and 557 for the "PED
RNA Detection Kit". The process of replication of a unique pig DNA fragment was evaluated by the fluorescence level at a wavelength of $557 \mathrm{~nm}$ for the "EXOone PEDV" test system and 520 for the "PED RNA Detection Kit". PCR quality was monitored by using positive control samples included in the kits. To control contamination, we used negative control samples that were obtained at the stage of extraction of nucleic acids (negative extraction control) also during the preparation of the reaction mixture and introduction of samples (negative control of amplification). Extraction of nucleic acid, preparation of the reaction mix and introduction of samples were carried out in three specialized rooms, by using laminar boxes of an abacterial environment.

Two-way analysis of variance (ANOVA), variation and statistical processing of the obtained results were performed by using the specialized software Statistica 6.0 (StatSoft Inc., USA). The significance of differences was assessed after verifying the experimental data which was obtained by using the Student t-test or its non-parametric counterpart - the Wilcoxon test. Selective parameters presented in the work have the following designations: " $\mathrm{x}$ " is the sample average; "SE" is the standard error of the average value. Changes between extraction kits were considered to be statistically significant at $\mathrm{P}<0.05,0.01$ and 0.001 . Two-factor ANOVA analyses determined the level of the impact of the studied methods of nucleic acid extraction (Kit 1-5) on the threshold value (Ct) using different test systems. The criterion for estimating the factor of the influence on the dependent variable of designations is F; critical value (minimally significant) of the impact factorFU; the indicator of statistical significance is " $P$ ".

\section{Results}

Comparison of the nucleic acid extraction protocol with different commercial kits. According to the manufacturer's recommendations, the shortest cell lysis time is suggested for Kit 1-5 minutes (Table 1).

Table 1

Comparison of the nucleic acid extraction protocol with different commercial kits

\begin{tabular}{lccccc}
\hline \multicolumn{1}{c}{$\begin{array}{c}\text { Extraction } \\
\text { Protocol Options }\end{array}$} & Kit 1 & Kit2 & Kit3 & Kit4 & Kit 5 \\
\hline $\begin{array}{l}\text { Duration of lysis, min } \\
\text { Incubation temperature }\end{array}$ & 5 & 10 & 10 & 15 & 12 \\
$\begin{array}{l}\text { during lysis, }{ }^{\circ} \mathrm{C} \\
\text { Proteinase }\end{array}$ & - & $22-24$ & 65 & $22-24$ & 75 \\
Carrier RNA & - & - & - & + & + \\
The sorption matrix & $\begin{array}{l}\text { Silicon } \\
\text { dioxide membrane }\end{array}$ & Silicate & Silicate & Silicate & $\begin{array}{c}\text { Magnetic } \\
\text { balls }\end{array}$ \\
$\begin{array}{l}\text { Number of rinsing steps } \\
\text { The volume }\end{array}$ & 3 & 2 & 3 & 2 & 3 \\
$\begin{array}{l}\text { of the solution for elution } \\
\text { Extraction time }\end{array}$ & 100 & 100 & 100 & 100 & 100 \\
of 1 sample, min & $45-50$ & $30-35$ & $30-35$ & $35-40$ & $35-40$ \\
\hline
\end{tabular}

Kits 2 and 3 have a 2 times longer period of exposure to cell lysis in the studied sample, compared to Kit 1 . The longest incubation period during chemical lysis is in kits 4 and 5, which are 3 and 2.4 times longer, respectively, than the period used during nucleic acid extraction with Kit 1 . The temperature of incubation during chemical cell lysis also differs significantly between sets. For kits 2 and 4 the temperature should be within room temperature, while for kits 1,3 and 5 it should be within $65-75^{\circ} \mathrm{C}$, which requires special equipment. Only two commercial kits contained a proteinase enzyme (kits 4 and 5), and only Kit 4 has Carrier RNA. Sorption of nucleic acids in Kit 1 occurs with a $10 \%$ suspension of silicon dioxide, in kits 2, 3 and 4 with a silicate membrane fixed in a centrifuge column, and Kit 5 with magnetic balls. Given the importance of rinsing the adsorbed nucleic acids from impurities, one should note that the number of nucleic acid rinsing steps from PCR inhibitor impurities is also different, in particular for kits 1,3 and 5, three detergent treatment steps should be carried out. At the same time, kits 2 and 4 have one stage less than the previous ones.

Analysis of the time for extraction of nucleic acids from 1 sample indicates that the shortest time has an extraction protocol in kits 2 and 3, and is the longest in Kit 1, which in the first case is associated with the use of a silicate membrane fixed in the centrifuge column. Therefore, the 
number of rinsing steps of adsorbed nucleic acids may be less. However, for Kit 1 the long time is due to the use of a silicon sorbent suspension, which requires a more thorough rinsing of impurities, even against the background of the shortest incubation period during chemical lysis. Consequently, the longest sequence of the nucleic acid extraction procedure is offered in Kit 1, and the fastest in kits 2 and 3. Kits 4 and 5 contain more auxiliary components that are supposed to improve nucleic acid extraction. At the same time, the nucleic acid extraction protocol in kits 4 and 2 consists of only 2 phases of foreign substance purification, which may affect the adequacy of the PCR results.

Extraction of PED virus RNA from small intestine tissue samples according to the manufacturer's recommendations. The results of studies to determine the quality of RNA extraction of the PED virus from the tissues of the small intestine using the studied commercial kits according to the instructions for their use by RT-PCR-RT showed that, when using the "EXOone PEDV" test system, the highest values of Ct by the cDNA detection channel of the PED virus were for kits 1 and 2 (Table 2).

Table 2

Results of cDNA amplification from RNA of the PED virus extracted with various commercial kits, $\mathrm{Ct}(\mathrm{x} \pm \mathrm{SE}, \mathrm{n}=5)$

\begin{tabular}{lcc}
\hline \multicolumn{2}{c}{$\begin{array}{c}\text { Extraction } \\
\text { kit }\end{array}$} & \multicolumn{2}{c}{ Test kits for PCR diagnosis of PED } \\
\cline { 2 - 3 } Kit 1 & "EXOone PEDV" & "PED RNA Detection Kit" \\
Kit 2 & $22.72 \pm 0.04^{\mathrm{a}}$ & $25.19 \pm 0.07^{\mathrm{a}}$ \\
Kit 3 & $22.61 \pm 0.06^{\mathrm{a}}$ & $27.64 \pm 0.05^{\mathrm{b}}$ \\
Kit 4 & $17.79 \pm 0.19^{\mathrm{b}}$ & $20.14 \pm 0.18^{\mathrm{c}}$ \\
Kit 5 & $16.95 \pm 0.33^{\mathrm{b}}$ & $18.62 \pm 0.24^{\mathrm{d}}$ \\
\hline
\end{tabular}

Note: different letters indicate the values significantly different one from another within the column of the Table on the results of comparison $(\mathrm{P}<0.05)$.

The corresponding index range between 22.61-22.72 Un. The $\mathrm{Ct}$ values for the use of the other three kits are probably less than the 4.8 data above for Kit $3(\mathrm{P}<0.01)$, by $5.72 \mathrm{Un}$ for Kit $4(\mathrm{P}<0.01)$ and 5.5 Un for Kit $5(\mathrm{P}<0.01)$ relative to the values of the Kit 1 and Kit 2. A similar ratio of indicators was obtained during the testing of samples using the test system "PED RNA Detection Kit". The highest Ct values were in the samples, the nucleic acids of which were extracted with Kit 1 and Kit 2. The Ct in the samples extracted with Kit 3, Kit 4 and Kit 5 was authentically lower by 5.1, 6.6 and $5.5 \mathrm{Un}(\mathrm{P}<0.01)$ relative to the values obtained by Kit 1 and less by 7.5, 9.1 and 7.9 Un $(\mathrm{P}<$ 0.01 ) relative to the values obtained by Kit 2 . Therefore, all commercial kits successfully extract RNA of the PED virus from the tissue homogenate of the small intestine of piglets. The highest amount of PCR suitable for PED RNA testing, according to the manufacturers' recommended nucleic acid purification parameters, is extracted using Kit 3, Kit 4 and Kit 5.

Extraction of porcine genomic DNA from small intestine tissue samples according to the manufacturers' recommendations. According to the results of studies of the efficiency of pig DNA extraction, it was found that during PCR using the EXOone PEDV test system, the $\mathrm{Ct}$ values for the Kit 1 and Kit 2 sets varied within 24-25 Un (Table 3).

Table 3

Results of amplification of a unique pig DNA fragment extracted with various commercial kits, $\mathrm{Ct}(\mathrm{x} \pm \mathrm{SE}, \mathrm{n}=5)$

\begin{tabular}{lcc}
\hline \multicolumn{1}{c}{$\begin{array}{c}\text { Extraction } \\
\text { kit }\end{array}$} & \multicolumn{2}{c}{ Test kits for PCR diagnosis of PED } \\
\cline { 2 - 3 } Kit 1 & "EXOone PEDV" & "PED RNA Detection Kit" \\
Kit 2 & $24.34 \pm 0.16^{\mathrm{a}}$ & $25.04 \pm 0.35^{\mathrm{a}}$ \\
Kit 3 & $25.30 \pm 0.19^{\mathrm{b}}$ & $25.07 \pm 0.09^{\mathrm{a}}$ \\
Kit 4 & $19.54 \pm 0.15^{\mathrm{c}}$ & $24.04 \pm 0.08^{\mathrm{b}}$ \\
Kit 5 & $27.45 \pm 0.61^{\mathrm{d}}$ & $22.15 \pm 0.08^{\mathrm{c}}$ \\
\hline
\end{tabular}

Note: different letters indicate the values significantly different one from another within the column of the Table on the results of comparison $(\mathrm{P}<0.05)$.

The lowest $\mathrm{Ct}$ values were found in the samples extracted using Kit 3 and Kit 5, which averaged 4.8 and $4.1 \mathrm{Un}$, respectively, $\mathrm{Ct}$ is smaller than Kit 1 and Kit 2. The highest $\mathrm{Ct}$ was found in nucleic acid samples extracted using Kit 4, which is significantly higher than the $\mathrm{Ct}$ for the above kits by an average of $5.1 \mathrm{Un}$ and is $27.45 \pm 0.61 \mathrm{Un}(\mathrm{P}<0.01)$.
A comparative analysis of the efficiency of pig genomic DNA extraction using the "PED RNA Detection Kit" showed that the amplification results of the samples extracted with Kit 1, Kit 2, Kit 3 and Kit 5 did not differ significantly from the above. Thus, the highest $\mathrm{Ct}$ value for the porcine sample gene was found in the samples extracted with Kit 1 and Kit 2, which range between $25 \mathrm{Un}$. The $\mathrm{Ct}$ values for Kit 3 and Kit 5 are smaller than Kit 1 and Kit 2 by 1.02 and 1.49 Un, respectively. The lowest $\mathrm{Ct}$ value was detected in the samples extracted by using Kit 4, which is likely to be less than the Ct values for Kit 1 by 2.89 Un, Kit 2 by $2.92 \mathrm{Un}$ and Kit 3 at $1.89 \mathrm{Un}(\mathrm{P}<0.01)$. Therefore all commercial kits successfully extract genomic DNA of pigs from the small intestine tissue homogenate. The largest amount of porcine DNA, according to the manufacturers' recommended nucleic acid purification parameters, is extracted using Kit 3 and Kit 5.

The analyses of the obtained results established that the choice of nucleic acid extraction method is of great importance when using separate kits of reagents to identify the $\mathrm{PED}$ virus $(\mathrm{F}=1286.9>\mathrm{FU}=2.618$; $\mathrm{P}<0.001$ ). Moreover, the choice of test system (according to the features of the extraction method), to a somewhat lesser extent affects the threshold value $(\mathrm{Ct})$ than the method of extraction of nucleic acids (Kit 1-5) $-\mathrm{F}=1093.6>\mathrm{FU}=4.08 ; \mathrm{P}<0.001)$ (Table 4).

\section{Table 4}

Results of two-factor ANOVA of the effect of different methods of nucleic acid extraction on the threshold value $(\mathrm{Ct})$ using different test systems

\begin{tabular}{|c|c|c|c|c|c|c|}
\hline Source of variation & SS & $\mathrm{df}$ & MS & $\mathrm{F}$ & $\mathrm{P}$ & FU \\
\hline \multicolumn{7}{|c|}{ Unique fragment of the PED virus RNA } \\
\hline Kit $1-5$ & 468.3 & 4 & 117.1 & 1286.9 & $1.15^{-41}$ & 2.61 \\
\hline Test kits for PCR & 99.5 & 1 & 99.5 & 1093.6 & $1.14^{-30}$ & 4.08 \\
\hline Interaction & 15.6 & 4 & 3.9 & 42.8 & $6.07^{-14}$ & 2.61 \\
\hline Internal & 3.6 & 40 & 0.091 & - & - & - \\
\hline Total & 587.0 & 49 & - & - & - & - \\
\hline \multicolumn{7}{|c|}{ Unique pig DNA fragment } \\
\hline Kit $1-5$ & 112.6 & 4 & 28.1 & 142.1 & $4.5^{-23}$ & 2.61 \\
\hline Test kits for PCR & 4.2 & 1 & 4.2 & 21.4 & $3.9^{-5}$ & 4.08 \\
\hline Interaction & 144.3 & 4 & 36.1 & 182.0 & $4.3^{-25}$ & 2.61 \\
\hline Internal & 7.9 & 40 & 0.198 & - & - & - \\
\hline Total & 269.0 & 49 & - & - & - & - \\
\hline
\end{tabular}

A similar pattern was found when the reagent kits were used to identify the IPC, but this dependence was by an order less. In particular, the effect of the method of extraction of nucleic acids on the threshold value was $-\mathrm{F}=142.1>\mathrm{FU}=2.62 ; \mathrm{P}<0.001$, and the impact of test system choice $-\mathrm{F}=21.4<\mathrm{FU}=4.08 ; \mathrm{P}<0.001$. It should be noted that there is a significant link between the choice of various methods of nucleic acids extraction (Kit 1-5) and the application of test systems of different manufacturers $(\mathrm{F}=42.8-182.0>\mathrm{FU}=2.61 ; \mathrm{P}<0.001)$. Therefore, selection of the method of nucleic acid extraction should take into account the characteristics of the test system of a particular manufacturer, regardless of its limited specification (PEDV or IPC).

Extraction of PED virus RNA was performed from the small intestine tissue homogenate of piglets with commercial kits by using a different weight of samples. According to the results of cDNA amplification of the PED virus using the "EXOone PEDV" test system, the lowest $\mathrm{Ct}$ values for the Kit 4, Kit 3 and Kit 5 were detected using $10 \mathrm{mg}$ samples (Table 5).

\section{Table 5}

Results of cDNA amplification from PED RNA using the "EXOone PEDV" test system extracted with commercial kits from samples of homogenate of intestine of different weights, $\mathrm{Ct}(\mathrm{x} \pm \mathrm{SE}, \mathrm{n}=5)$

\begin{tabular}{lcccc}
\hline Extraction & \multicolumn{3}{c}{ Weight of sample for extraction, mg } \\
\cline { 2 - 5 } \multicolumn{1}{c}{ kit } & 10 & 50 & 100 & 200 \\
\hline Kit 1 & $32.23 \pm 0.21^{\mathrm{a}}$ & $31.49 \pm 0.17^{\mathrm{a}}$ & $22.72 \pm 0.34^{\mathrm{b}}$ & $20.45 \pm 0.15^{\mathrm{c}}$ \\
Kit 2 & $30.59 \pm 0.24^{\mathrm{a}}$ & $29.77 \pm 0.21^{\mathrm{a}}$ & $22.61 \pm 0.46^{\mathrm{b}}$ & $21.09 \pm 0.16^{\mathrm{b}}$ \\
Kit 3 & $16.74 \pm 0.20^{\mathrm{a}}$ & $16.97 \pm 0.15^{\mathrm{a}}$ & $17.79 \pm 0.19^{\mathrm{a}}$ & $26.62 \pm 0.15^{\mathrm{b}}$ \\
Kit 4 & $15.96 \pm 0.30^{\mathrm{a}}$ & $16.03 \pm 0.11^{\mathrm{a}}$ & $16.95 \pm 0.33^{\mathrm{a}}$ & $21.74 \pm 0.13^{\mathrm{b}}$ \\
Kit 5 & $16.79 \pm 0.12^{\mathrm{a}}$ & $17.18 \pm 0.12^{\mathrm{a}}$ & $17.28 \pm 0.23^{\mathrm{a}}$ & $22.44 \pm 0.44^{\mathrm{b}}$ \\
\hline
\end{tabular}

Note: different letters indicate the values significantly different one from another within a line of the Table on the results of comparison $(\mathrm{P}<0.05)$. 
An increase in the weight of the test material contributes to an increase in the $\mathrm{Ct}$ in the samples extracted by using Kit 3, Kit 4 and Kit 5. However, no significant difference was found between samples weighing 10 and $50 \mathrm{mg}$ when using commercial kits 3, 4 and 5. A probable difference is observed in the study of nucleic acid samples extracted from $200 \mathrm{mg}$ samples. For Kit 3, the Ct value is increased by $9.88 \mathrm{Un}(\mathrm{P}<$ $0.01)$, for Kit 4 at $5.78 \mathrm{Un}(\mathrm{P}<0.01)$, for Kit 4 by $5.47 \mathrm{Un}(\mathrm{P}<0.01)$, compared to the $\mathrm{Ct}$ values obtained during the study of samples extracted from samples weighing $10 \mathrm{mg}$. The amplification results of the extracts obtained from Kit 1 and Kit 2 reflect an inverse relationship with the results obtained from Kit 3, Kit 4 and Kit 5. Thus, the Ct values in the $10 \mathrm{mg}$ extracts for Kit 1 and Kit 2 are the highest. Increasing the weight of the samples to be extracted with these kits decreases the Ct for cDNA of the PED virus. It should be noted that, similarly to the aforementioned kits 3, 4, 5, no significant difference was found between the $\mathrm{Ct}$ values obtained from 10 and $50 \mathrm{mg}$. Analysis of the results of cDNA amplification of the PED virus indicates a decrease in $\mathrm{Ct}$ in samples with a weight of 100 and $200 \mathrm{mg}$ samples. Thus, for Kit 1 , the $\mathrm{Ct}$ value is probably less by $9.51 \mathrm{Un}$ and 11.78 Un ( $\mathrm{P}<0.05-0.01)$, and for Kit $2-$ by 7.98 and 9.50 Un $(\mathrm{P}<$ $0.05-0.01)$. The results of cDNA amplification of the PED virus in the samples tested with the test kit "PED RNA Detection Kit" are similar to the previous ones. The results of studies of samples with a weight of 10 mg samples showed that Kit 1 and Kit 2 have the highest values of $\mathrm{Ct}$, and Kit 3, Kit 4 and Kit 5 the smallest (Table 6).

\section{Table 6}

The results of cDNA amplification from PED virus RNA using the "PED RNA Detection Kit" extracted from commercially available kits of various weights $(\mathrm{Ct}, \mathrm{x} \pm \mathrm{SE}, \mathrm{n}=5)$

\begin{tabular}{lcccc}
\hline \multirow{2}{*}{$\begin{array}{c}\text { Extraction } \\
\text { kit }\end{array}$} & 10 & 50 & 100 & 200 \\
\cline { 2 - 5 } Kit 1 & $35.60 \pm 0.38^{\mathrm{a}}$ & $33.98 \pm 0.41^{\mathrm{a}}$ & $25.19 \pm 0.27^{\mathrm{b}}$ & $23.28 \pm 0.19^{\mathrm{b}}$ \\
Kit 2 & $34.36 \pm 0.44^{\mathrm{a}}$ & $34.97 \pm 0.35^{\mathrm{a}}$ & $27.64 \pm 0.15^{\mathrm{b}}$ & $25.87 \pm 0.21^{\mathrm{b}}$ \\
Kit 3 & $19.83 \pm 0.17^{\mathrm{a}}$ & $20.16 \pm 0.11^{\mathrm{a}}$ & $20.14 \pm 0.18^{\mathrm{a}}$ & $23.69 \pm 0.28^{\mathrm{b}}$ \\
Kit 4 & $17.51 \pm 0.28^{\mathrm{a}}$ & $17.86 \pm 0.16^{\mathrm{a}}$ & $18.62 \pm 0.24^{\mathrm{a}}$ & $23.27 \pm 0.31^{\mathrm{b}}$ \\
Kit 5 & $18.25 \pm 0.17^{\mathrm{a}}$ & $19.63 \pm 0.15^{\mathrm{a}}$ & $19.71 \pm 0.31^{\mathrm{a}}$ & $25.04 \pm 0.52^{\mathrm{b}}$ \\
\hline
\end{tabular}

Note: different letters indicate the values significantly different one from another within a line of the Table on the results of comparison $(\mathrm{P}<0.05)$.

No significant difference between the PCR results of the PED RNA samples extracted with commercial kits 3,4 , and 5 with 10,50 , and $100 \mathrm{mg}$ was found, but a tendency to increase in $\mathrm{Ct}$ at the same time as the weight of the samples to be extracted should be noted. The highest $\mathrm{Ct}$ values were found in samples weighing $200 \mathrm{mg}$. Thus, for Kit 3 , the value in the sample with a weight of $200 \mathrm{mg} C t$ is greater by $3.86 \mathrm{Un}(\mathrm{P}<0.05)$, for Kit 4 by $5.76 \mathrm{Un}(\mathrm{P}<0.01)$, and for Kit 5 it was $6.79 \mathrm{Un}(\mathrm{P}<0.01)$, compared to the values of samples weighing $10 \mathrm{mg}$. The results of the amplification of samples of extracted nucleic acids with kits 1 and 2 indicate a significant difference between the $\mathrm{Ct}$ values obtained from the extraction of nucleic acids from a material weighing $10-50$ and $100-200 \mathrm{mg}$. Thus, the value of $\mathrm{Ct}$ for Kit 1 and Kit 2 in a sample with a weight of $100 \mathrm{mg}$ of specimen is probably lower by $10.41 \mathrm{Un}(\mathrm{P}<0.05)$ and $6.72 \mathrm{Un}$, respectively $(\mathrm{P}<0.05)$ compared to the values obtained from the samples by weight of $10 \mathrm{mg}$, and accordingly by $8.79 \mathrm{Un}(\mathrm{P}<0.01)$ and $7.33 \mathrm{Un}(\mathrm{P}<$ 0.05 ) compared to the values obtained from samples weighing $50 \mathrm{mg}$. The values of $\mathrm{Ct}$ for Kit 1 and Kit 2 in the sample with a weight of 200 mg samples are probably lower by $12.32 \mathrm{Un}(\mathrm{P}<0.001)$ and $8.49 \mathrm{Un}$, respectively $(\mathrm{P}<0.001)$ compared to the values obtained from samples weighing $10 \mathrm{mg}$ and $10.7 \mathrm{Un}$, respectively $(\mathrm{P}<0.01)$ and $9.10 \mathrm{Un}(\mathrm{P}<$ 0.01 ) compared to the values obtained from samples weighing $50 \mathrm{mg}$.

Therefore, according to the results of cDNA amplification of the PED virus, the smallest $\mathrm{Ct}$ values were detected in the samples extracted with Kit 3, Kit 4 and Kit 5 from $10 \mathrm{mg}$ samples. Increasing the weight of the samples to $200 \mathrm{mg}$ increases the $\mathrm{Ct}$ for Kit 3, Kit 4 and Kit 5 by an average of $6.87 \mathrm{Un}, 5.77 \mathrm{Un}$ and $6.13 \mathrm{Un}$ respectively, compared to the values obtained from samples weighing $10 \mathrm{mg}$. The highest $\mathrm{Ct}$ values were found in the samples extracted with Kit 1 and Kit 2 from $10 \mathrm{mg}$ samples. Increasing the sample weight to $200 \mathrm{mg}$ reduces the $\mathrm{Ct}$ for these commercial kits by an average of 12.05 Un and 8.99 Un respecttively, compared to the values obtained from samples weighing $10 \mathrm{mg}$.
Extraction of porcine genomic DNA from the small intestine tissue homogenate by commercial kits of different sample weights. Analysis of the results of amplification of a unique DNA fragment of pig extracted from intestinal homogenate of different weights showed that Kit 1 and Kit 2 more effectively extract genomic DNA from samples weighing $200 \mathrm{mg}$, and Kit 3, Kit 4 and Kit 5 from samples weighing $10 \mathrm{mg}$ (Table 7).

\section{Table 7}

The results of amplification of a unique pig DNA fragment using the "EXOone PEDV test system" extracted with commercial kits $(\mathrm{Ct}, \mathrm{x} \pm \mathrm{SE}, \mathrm{n}=5)$

\begin{tabular}{lcccc}
\hline Extraction & \multicolumn{3}{c}{ Weights of sample for extraction, mg } \\
\cline { 2 - 5 } \multicolumn{1}{c}{ Kit } & 10 & 50 & 100 & 200 \\
\hline Kit 1 & $29.49 \pm 0.21^{\mathrm{a}}$ & $28.26 \pm 0.18^{\mathrm{a}}$ & $24.34 \pm 0.26^{\mathrm{b}}$ & $21.19 \pm 0.25^{\mathrm{c}}$ \\
Kit 2 & $28.20 \pm 0.29^{\mathrm{a}}$ & $27.60 \pm 0.17^{\mathrm{a}}$ & $25.30 \pm 0.19^{\mathrm{b}}$ & $25.04 \pm 0.22^{\mathrm{b}}$ \\
Kit 3 & $17.53 \pm 0.26^{\mathrm{a}}$ & $18.20 \pm 0.34^{\mathrm{a}}$ & $19.54 \pm 0.25^{\mathrm{a}}$ & $23.12 \pm 0.32^{\mathrm{b}}$ \\
Kit 4 & $25.32 \pm 0.28^{\mathrm{a}}$ & $26.12 \pm 0.23^{\mathrm{a}}$ & $27.45 \pm 0.61^{\mathrm{a}}$ & $28.51 \pm 0.15^{\mathrm{b}}$ \\
Kit 5 & $19.71 \pm 0.19^{\mathrm{a}}$ & $19.54 \pm 0.13^{\mathrm{a}}$ & $20.33 \pm 0.39^{\mathrm{a}}$ & $21.30 \pm 0.28^{\mathrm{b}}$ \\
\hline
\end{tabular}

Note: different letters indicate the values significantly different one from another within a line of the Table on the results of comparison $(\mathrm{P}<0.05)$.

The smallest $\mathrm{Ct}$ values were detected in the samples extracted from the sample by $10 \mathrm{mg}$ with Kit 3 and Kit 5 . Extraction of nucleic acids from a sample weighing $200 \mathrm{mg}$ contributed to a significant increase in the $\mathrm{Ct}$ for Kit 3 by $5.59 \mathrm{Un}(\mathrm{P}<0.01)$, and for Kit 5 by $1.59 \mathrm{Un}$, compared to the values obtained from the sample by weight of $10 \mathrm{mg}$, and respecttively $4.92 \mathrm{Un}(\mathrm{P}<0.05)$ and $1.76 \mathrm{Un}$, compared to the values obtained from the sample by weight of $50 \mathrm{mg}$. Analysis of the results of pig DNA amplification for Kit 4 indicates less efficient extraction of genomic DNA from intestinal tissues by the method proposed by this manufacturer. This conclusion is confirmed by the obtained results of $\mathrm{Ct}$ values.

The results of the amplification of a unique DNA fragment of a pig by using the test system "Kit for detection of RNA of the PED virus" extracted from various mass samples by using different commercial kits are similar to the previous ones (Table 8).

\section{Table 8}

The results of amplification of a unique DNA fragment of a pig by using the test system "Kit for detection of RNA of the PED virus" extracted from samples of different masses with commercial kits $(\mathrm{Ct}, \mathrm{x} \pm \mathrm{SE}, \mathrm{n}=5)$

\begin{tabular}{lcccc}
\hline Extraction & \multicolumn{3}{c}{ Weights of sample for extraction, mg } \\
\cline { 2 - 5 } \multicolumn{1}{c}{ kit } & 10 & 50 & 100 & 200 \\
\hline Kit 1 & $31.73 \pm 0.47^{\mathrm{a}}$ & $30.45 \pm 0.31^{\mathrm{a}}$ & $25.04 \pm 0.35^{\mathrm{b}}$ & $24.05 \pm 0.40^{\mathrm{b}}$ \\
Kit 2 & $31.08 \pm 0.31^{\mathrm{a}}$ & $30.28 \pm 0.42^{\mathrm{a}}$ & $26.15 \pm 0.23^{\mathrm{b}}$ & $25.07 \pm 0.29^{\mathrm{b}}$ \\
Kit 3 & $21.40 \pm 0.14^{\mathrm{a}}$ & $21.55 \pm 0.05^{\mathrm{a}}$ & $23.19 \pm 0.24^{\mathrm{b}}$ & $24.04 \pm 0.28^{\mathrm{b}}$ \\
Kit 4 & $19.68 \pm 0.11^{\mathrm{a}}$ & $20.05 \pm 0.17^{\mathrm{a}}$ & $22.15 \pm 0.38^{\mathrm{b}}$ & $27.19 \pm 0.37^{\mathrm{c}}$ \\
Kit 5 & $21.04 \pm 0.23^{\mathrm{a}}$ & $21.15 \pm 0.16^{\mathrm{a}}$ & $23.57 \pm 0.28^{\mathrm{b}}$ & $25.18 \pm 0.48^{\mathrm{c}}$ \\
\hline
\end{tabular}

Note: different letters indicate the values significantly different one from another within a line of the Table on the results of comparison $(\mathrm{P}<0.05)$.

Thus, the highest $\mathrm{Ct}$ values were detected in samples extracted with commercial kits 1 and 2 from intestinal tissue homogenate with a sample weight of $10 \mathrm{mg}$. Extraction of nucleic acids by these kits from samples weighing $50 \mathrm{mg}$ did not significantly affect the result of amplification, whereas the isolation of nucleic acids from samples weighing $100 \mathrm{mg}$ significantly reduced the $\mathrm{Ct}$ by $6.69 \mathrm{Un}(\mathrm{P}<0.05)$ and $4.93 \mathrm{Un}$ $(\mathrm{P}<0.05)$, compared to the values obtained from samples weighing $10 \mathrm{mg}$, and accordingly by $5.41 \mathrm{Un}(\mathrm{P}<0.05)$ and $4.13 \mathrm{Un}(\mathrm{P}<0.05)$, compared to the values obtained from samples weighing $50 \mathrm{mg}$. The minimum $\mathrm{Ct}$ values for Kit 1 and Kit 2 are set for the extraction of nucleic acids from $200 \mathrm{mg}$ samples. They are significantly smaller at 7.68 Un $(\mathrm{P}<0.01)$ and $6.01 \mathrm{Un}(\mathrm{P}<0.05)$ compared to the values obtained from the samples by weight of $10 \mathrm{mg}$, and accordingly by $6.40 \mathrm{Un}(\mathrm{P}<0.05)$ and 5.21 Un $(\mathrm{P}<0.05)$, compared to the values obtained from samples weighing $50 \mathrm{mg}$.

The most effective extraction of genomic DNA was achieved with Kit 3, Kit 4 and Kit 5 from 10 mg samples, as indicated by the amplification results of a unique porcine DNA fragment that had the lowest $\mathrm{Ct}$ value among all the kits tested. There was a tendency for this parameter to increase in samples with a weight of $100 \mathrm{mg}$, which for Kit 3, Kit 4 
and Kit 5 are respectively 1.79 Un, 2.47 Un $(\mathrm{P}<0.05)$ and 2.53 Un compared to the values obtained from samples weighing $10 \mathrm{mg}$. A significant increase in $\mathrm{Ct}$ was detected by nucleic acid extraction with Kit 3 , Kit 4, and Kit 5 from $200 \mathrm{mg}$ samples by $2.64 \mathrm{Un}$, respectively (P $<$ 0.05), 7.51 Un $(\mathrm{P}<0.01)$ and $4.14 \mathrm{Un}(\mathrm{P}<0.05)$ compared to the values obtained from samples weighing $10 \mathrm{mg}$.

The choice of nucleic acid extraction method is determinative when the reagent kits are used to identify both PEDV and IPC, ( $F=1892$ $2566>\mathrm{FU}=2.49 ; \mathrm{P}<0.001$ ) (Table 9).

\section{Table 9}

Two-factor ANOVA of the influence of various methods of nucleic acid extraction on the threshold value $(\mathrm{Ct})$ in the comparative analysis of the variable homogenate volume

\begin{tabular}{lrrrccc}
\hline Source of variation & SS & df & MS & F & P & FU \\
\hline \multicolumn{7}{c}{ PEDV } \\
\hline Kit 1-5 & 1512.0 & 4 & 378.0 & 2565.8 & $1.4^{-83}$ & 2.49 \\
The mass of the homogenate & 176.5 & 3 & 58.8 & 399.4 & $5.1^{-48}$ & 2.72 \\
Interaction & 1294.5 & 12 & 107.9 & 732.2 & $1.9^{-76}$ & 1.88 \\
Internal & 11.8 & 80 & 0.147 & - & - & - \\
Total & 2994.7 & 99 & - & - & - & - \\
\hline \multicolumn{7}{c}{ IPC } \\
\hline Kit 1-5 & 1030.3 & 4 & 257.6 & 1891.7 & $2.5^{-78}$ & 2.49 \\
The mass of the homogenate & 6.0 & 3 & 2.0 & 14.6 & $1.1^{-7}$ & 2.72 \\
Interaction & 381.7 & 12 & 31.8 & 233.6 & $5.7^{-57}$ & 1.88 \\
Internal & 10.9 & 80 & 0.136 & - & - & - \\
Total & 1428.8 & 99 & - & - & - & - \\
\hline
\end{tabular}

Moreover, relative to the threshold value, the selection of the mass of the homogenate has a much greater impact when the kits of PEDV reagents were used $(\mathrm{F}=399.4>\mathrm{FU}=2.72 ; \mathrm{P}<0.001)$ than the IPC kits $(\mathrm{F}=14.6>\mathrm{FU}=2.72 ; \mathrm{P}<0.001)$. A significant link was established between the choice of different methods of nucleic acid extraction (Kit 1-5) and the mass of homogenates (10, 50, 100 and $200 \mathrm{mg}$ ) $\mathrm{F}=233.6-732.2>\mathrm{FU}=1.88 ; \mathrm{P}<0.001)$.

Therefore, the largest amount of genomic DNA from intestinal tissues is extracted with Kit 3, Kit 4, and Kit 5 from $10 \mathrm{mg}$ samples. Increasing the sample weight to $200 \mathrm{mg}$ increases the $\mathrm{Ct}$ for Kit 3, Kit 4 and Kit 5 by an average of $4.12 \mathrm{Un}, 5.35 \mathrm{Un}$ and $2.87 \mathrm{Un}$ respectively, compared to the values obtained from samples weighing $10 \mathrm{mg}$. The highest $\mathrm{Ct}$ values were found in the samples extracted with Kit 1 and Kit 2 from $10 \mathrm{mg}$ samples. Increasing the sample weight to $200 \mathrm{mg}$ reduces the average $\mathrm{Ct}$ for these sets by an average of $7.99 \mathrm{Un}$ and 4.59 Un accordingly, compared to the values obtained from samples weighing $10 \mathrm{mg}$.

\section{Discussion}

The process of nucleic acid extraction is one of the important steps for molecular genetic studies, in particular PCR, as it directly affects the efficiency of PCR, which depends on the concentration of the extracted nucleic acids of the eluate, the degree of their destruction and the level of purification of the nucleic acid solution. Today there are many different methods for nucleic acid extraction and modification, on the basis of which commercial DNA/RNA extraction kits are optimized for a variety of research sites (Hu et al., 2014; Wang et al., 2016). Thanks to this, the cleaning protocol of each set has its own peculiarities. At the same time, the basic stages of extraction - cell lyses of the test samples, sorption of nucleic acids in the solid phase, laundering of impurities and elution to form a pure nucleic acid solution, remain the same for most commercial kits. The results of comparative analysis of the main indicators of DNA/RNA isolation showed that the shortest stage of cell lysis is contained in the Kit 1 protocol, and the longest in the kits 4 and 5 . Longer time of the isolation is requested for hydrolyzes peptide bonds from the carboxyl group of aliphatic, aromatic and hydrophobic amino acids even in the presence of detergents. It should be noted that Kit 4 contains a carrier RNA component which increases the efficiency of RNA molecules deposition and short-stranded DNA fragments.

Selective sorption of nucleic acids, their separation and concentration are interdependent steps carried out consecutively with the use of liquid and solid phase steps. The application of these steps provides se- lective separation of the sample molecules, which is based on the specific hydrophobic, ionic properties and polarity of the solution and the sorption solid-phase reagent. Our test kits for extraction are based on three major solids' varieties for sorption of nucleic acid molecules: Kit 1 $10 \%$ suspension of silicon dioxide, kits 2, 3 and 4 - on a silicate membrane fixed in a centrifuge column and on a magnetic column - Kit 5 . The basis of the solid-phase method is to create numerous weak chemical bonds between the sorbent and the sample DNA/RNA molecule. First of all, nucleic acid molecules are adsorbed on the solid phase due to electrostatic and Van der Waals interactions (Biziuk, 2006; Thatcher, 2015).

For the first time in 1979, it was shown that the silicate matrix has a high affinity for DNA molecules under alkaline $\mathrm{pH}$ and increased salt concentration in the reaction mixture. Inorganic counter-ions compensate for the charge of DNA molecules, reduce the size of the counter-ion shell and promote adsorption (Siegel et al., 2017). The mechanism of selective binding of nucleic acid molecules and the silicate matrix consists in the affine interaction of negatively charged DNA and RNA molecules and positively charged silicate material, with other cell components and chemicals being removed during the rinsing step. A desorption of nucleic acids from the surface of the silicate matrix occurs when adding a hypoosmotic solution, in particular the nuclease-free buffer of Tris-EDTA. To date, numerous modifications and additions have been made to the method, which increase the efficiency of extraction of both the total amount of nucleic acids and their individual types. Thus, the addition of chaotropic agents leads to the denaturation of RNA enzymes and, accordingly reduces the degree of RNA degradation. The disadvantage of this method is the need for centrifugation of the test solution, which contributes to the degradation of nucleic acids by mechanical damage to whole DNA/RNA molecules (Michael et al., 2014).

One of the most common methods for solid-phase adsorption of RNA, genomic, plasmid and mitochondrial DNA forms is magnetic ball extraction (Merkle et al., 2014; Huckle, 2015). The method is based on the separation of nucleic acids from the total mixture of cell components by complementary hybridization (Azimi et al., 2011). This method of procedure does not contain a centrifugation step, which reduces the risks of degradation of nucleic acids and provides alternative ways of automating the extraction process. In addition to the aforementioned advantages, the method is easy to apply and characterized by high speed, with several samples being examined simultaneously. As we noted, the extraction time of Kit 5 is 35-40 min regardless of the number of samples tested from 1 to 32 . On the other hand, the use of other test kits for the extraction of nucleic acids requires additional time to perform a large number of samples, which subsequently are subject to simultaneous extraction. This significantly distinguishes Kit 5 from the other kits, it significantly shortens the time of the diagnostic procedure, which is important enough for laboratory confirmation of a diagnosis of PED.

It should be noted that the purification process is especially important during the extraction of nucleic acids from a rich material in low molecular weight substances that have inhibitory properties against enzymes, as well as enzymes that enhance the destruction of nucleic acids DNA and RNA. The level of purification of nucleic acids, their concentration and the degree of degradation of the sample molecules are the most critical factors affecting the effectiveness of molecular genetic studies. For methods such as DNA sequencing or hybridization, determining the quality of the nucleic acid test drug is a prerequisite for analysis. The use of a new extraction method or a procedure for the isolation of nucleic acids from a material predictably containing a small number of sample molecules in the presence of concomitant inhibitors should also be performed with the subsequent determination of the efficiency of the extraction process (Schrader et al., 2012).

The quality of nucleic acid extraction directly influences the level of fluorescence in PCR-RT studies. Fluorescence registration of the accumulation of amplification products entails special requirements for the background fluorescence of the sample and the presence of impurities denaturing the fluorescence sample within the sample. Thus, the residue of salts in the preparation of nucleic acids extracted from urine leads to the denaturation of fluorescent oligonucleotide samples and, accordingly, to an increase in background fluorescence (Yamada et al., 2012; Liu et al., 2016). In addition, the PCR method is sensitive to the residue in 
the samples of substances used in the selection: heparin or EDTA, it is a chelating agent, which leads to a decrease in the concentration of free magnesium in the reaction mixture and inhibition of PCR. It should be noted that the requirements for the purity of the preparation of nucleic acids are increased by conducting RT-PCR-RT, because the efficiency of synthesis of complementary DNA is directly proportional to the purity of the extracted sample of RNA.

The results of the study of the quality of RNA extraction of the PED virus from the tissues of the small intestine by the studied commercial kits by the RT-PCR-RT method for the diagnosis of PED showed that all the tested kits extracted RNA of the virus PED and virus genes from piglets' intestines in sufficient quantity according to the manufacturers' recommended parameters of purification of nucleic acids. The highest amount of virus RNA that is suitable for RT-PCR studies was extracted with Kit 3, Kit 4, and Kit 5, indicating low values of $\mathrm{Ct}$, and is inversely proportional to the concentration of the sample nucleic acid used in PCR. It was determined by the results of the study that the high efficiency of RNA extraction of the PED virus may be due to the adsorption properties of the matrices offered by the respective manufacturers. In addition, high-quality nucleic acid extraction using these kits is ensured by the presence of a proteinase that disrupts peptide bonds of cellular and membrane components of cells and promotes the release of large RNA/DNA molecules. It should be noted that the lowest $\mathrm{Ct}$ was detected in the samples extracted with Kit 4, which may be due to the use of carrier RNA in this kit, which, like tRNA, is an adjuvant in nucleic acid deposition. Compared to tRNA, carrier RNA immediately precipitates nucleic acid molecules, even short-chain fragments, in which the number of nucleotides exceeds 15 pairs immediately after being added to the solution.

Comparative PCR analysis of porcine DNA showed that Kit 3 and Kit 5 allow extraction of NK from the tissues of pig intestines better according to the manufacturers' recommended physicochemical cell lysis sequences, NK adsorption and purification compared to Kit 1, Kit 2 and Kit 4. The Ct values for the samples extracted with Kit 4 in this case are much greater than with Kit 3 and Kit 5. This is attributable to the competitive use of the nucleotide polymerase of the reaction mixture to replicate the cDNA sequence of the PED virus, which in the samples was significantly greater than a unique porcine DNA fragment that replicates with the cDNA of the PED virus (Lorenz, 2012). This is confirmed by the values of $\mathrm{Ct}$, which for cDNA of the PED virus is 16.95-18.62 Un, and for the unique fragment of pig DNA ranges from 22.15-27.45 Un. Furthermore, a significant link was established between the choice of different methods of nucleic acids' extraction (Kit 1-5) and the application of test systems of different manufacturers, which testifies to the excellent efficiency of the several methods of nucleic acids extraction using test systems of different manufacturers. Therefore, the method of extraction of nucleic acids should be selected taking into account the features of the test system of a particular manufacturer, regardless of whether the RNA of the PED virus or a unique pig DNA fragment is determined.

According to the results of the second stage of studies to determine the efficiency of extraction of nucleic acids from the tissues of the small intestine using 10, 50, 100 and $200 \mathrm{mg}$ of starting material, it was found that the quality of nucleic acid extraction depends not only on the method used, but also on the weight of the samples. It should be noted that the choice of nucleic acid extraction method is essential under conditions of using the reagent kits to identify cDNA of the PED virus or a unique sequence of porcine DNA. Moreover, relative to the threshold value the selection of the mass of the homogenate has a much greater impact with the use of a PEDV reagents kit compared with IPC. We established a significant relation between the choice of different methods of extraction of nucleic acids and the weight of the sample, which determines the functional dependence of the effectiveness of method of nucleic acids' extraction on the fitted mass of the samples of homogenate.

Thus, according to the results of cDNA amplification of the PED virus and a unique pig DNA fragment, it was found that the highest efficiency of extraction of genetic material for Kit 3, Kit 4 and Kit 5 sets was detected by using samples weighing $10 \mathrm{mg}$. It should be noted that the increase in mass of the material under study for these kits correlates with an increase in Ct. Thus, these data indicate the quality of nucleic acid ext- raction, which depends on the level of purification of RNA and DNA molecules from PCR inhibiting impurities. The relationship between extraction efficiency and the mass of material under test using Kit 1 and Kit 2 is the opposite of the above. Thus, the results of the analysis of Ct in samples with different weights of samples of the test material showed that the highest efficiency of extraction was detected in the samples weighing $200 \mathrm{mg}$ of intestinal homogenate, and the lowest - using $10 \mathrm{mg}$. The direct relationship between the efficiency of nucleic acid extraction and the weight of the starting material, using the two above kits, may be due to the low ability of binding of nucleic acid molecules to a silicate matrix with Kit 2 and silicon sorbent with Kit 1 and low efficiency of small fragments due to the increased affinity of the latter to the positively charged ions on the surface of the silicate matrix.

Therefore, the PCR studies of RNA of the PED virus and a unique pig DNA fragment indicate that the extraction of nucleic acids by commercial kits has different efficiency and depends on various factors. The most important of these are the adsorption capacity of the solid-phase sorbent, its configuration, and the nature that binds RNA and DNA molecules, the type of sample from which the extraction takes place, its volume, or the mass used for extraction.

\section{Conclusion}

The obtained results of comparative analysis of nucleic acid extraction using different protocols of commercial kits showed that all the proposed protocols allow sufficient extract from the intestinal tissue of RNA of the PED virus and genomic DNA of piglets for PCR studies. The most effective PED RNA extraction is by "ArtBioTech", "Bio Extract Column", and "Viral DNA/RNA Extraction Kit", and pig genomic DNA extracts by the "ArtBioTech" and "Viral DNA/RNA Extraction Kit" Ct. Thus, the "Bio Extract Column" adsorbent is more effective for RNA extraction of the PED virus. At the same time, "ArtBioTech" and "Viral DNA/RNA Extraction Kit" developed the efficacy in the extraction of genomic DNA of pigs. Moreover, the results obtained showed that the sample weight affects the quality of extraction of RNA of the PED virus and genomic DNA of pigs from the homogenate of pig intestinal tissues. For the "ArtBioTech", "Bio Extract Column" and "Viral DNA/RNA Extraction Kit" kits, the sample of $10 \mathrm{mg}$ homogenate is optimal for extraction of genetic material and $200 \mathrm{mg}$ for the "S-Sorb" and "FBioNucleo" kits. Thus, the selection of the DNA/RNA extraction methods is a critical step of PED virus diagnosis.

\section{References}

Akshara, G. (2018). Simple and efficient method for functional RNA extraction from tropical medicinal plants rich in secondary metabolites. Tropical Plant Research, 5(1), 8-13.

Ali, N., Rampazzo, R., Costa, A., \& Krieger, M. A. (2017). Current nucleic acid extraction methods and their implications to point-of-care diagnostics. BioMed Research International, 2017, 13.

Azimi, S. M., Nixon, G., Ahern, J., \& Balachandran, W. (2015). A magnetic bead-based DNA extraction and purification microfluidic device. Microfluidics and Nanofluidics, 11(2), 157-165.

Biziuk, M. (2006). Solid phase extraction technique - trends. Polish Journal of Environmental Studies, 15(5), 677-690.

Bjustrom-Kraft, J., Woodard, K., Giménez-Lirola, L., Rotolo, M., Wang, C., Sun, Y., Lasley, P., Zhang, J., Baum, D., Gauger, P., Main, R., \& Zimmerman, J. (2016). Porcine epidemic diarrhea virus (PEDV) detection and antibody response in commercial growing pigs. BMC Veterinary Research, 12, 99.

Busa, L. S. A., Mohammadi, S., Maeki, M., Ishida, A., Tani, H., \& Tokeshi, M. (2016). Advances in microfluidic paper-based analytical devices for food and water analysis. Micromachines, 7(5), 86.

Busin, V., Wells, B., Kersaudy-Kerhoas, M., Shu, W., \& Burgess, S. T. G. (2016) Opportunities and challenges for the application of microfluidic technologies in point-of-care veterinary diagnostics. Molecular and Cellular Probes, 30(5), 331-341.

Carvajal, A., Argüello, H., Martínez-Lobo, F. J., Costillas, S., Miranda, R., de Nova, P. J. G., \& Rubio, P. (2015). Porcine epidemic diarrhoea: New insights into an old disease. Porcine Health Management, 1(12), 1-8.

Chacon-cortes, D., Griffis, L., \& Chacon-Cortes, D. (2014). Methods for extracting genomic DNA from whole blood samples: current perspectives. Journal of Biorepository Science for Applied Medicine, 2, 1-9. 
Choi, E. H., Lee, S. K., Ihm, C., \& Sohn, Y. H. (2014). Rapid DNA extraction from dried blood spots on filter paper: Potential applications in biobanking. Osong Public Health and Research Perspectives, 5(6), 351-357.

Choudhury, B., Dastjerdi, A., Doyle, N., Frossard, J. P., \& Steinbach, F. (2016). From the field to the lab - an European view on the global spread of PEDV. Virus Research, 226(2), 40-49.

Cochrane, R. A., Dritz, S. S., Woodworth, J. C., Huss, A. R., Stark, C. R., Hesse, R. A., Zhang, J., Tokach, M. D., Bai, J., \& Jones, C. K. (2015). Evaluating chemical mitigation of porcine epidemic diarrhea virus (PEDV) in swine feed and ingredients. Kansas Agricultural Experiment Station Research Reports, 1, 7

Cui, F., Rhee, M., Singh, A., \& Tripathi, A. (2015). Microfluidic sample preparation for medical diagnostics. Annual Review of Biomedical Engineering, 17, 267-276.

El-Maklizi, M. A., Ouf, A., Ferreira, A., Hedar, S., \& Cruz-Rivera, E. (2014). A localized PCR inhibitor in a porcelain crab suggests a protective role. PeerJ, 2, e689.

Fong, E. J., Huang, C., Hamilton, J., Benett, W. J., Bora, M., Burklund, A., Metz, T.R., \& Shusteff, M. (2015). A microfluidic platform for precision smallvolume sample processing and its use to size separate biological particles with an acoustic microdevice. Joumal of Visualized Experiments, 105, 51-53.

Gerber, F., Xiao, P., Lager, C-T., Crawford, K., Kulshreshtha, K., V Cao, D., Meng, X-J., \& Opriessnig, T. (2016). Increased frequency of porcine epidemic diarrhea virus shedding and lesions in suckling pigs compared to nursery pigs and protective immunity in nursery pigs after homologous re-challenge. Veterinary Research, 47(1), 118.

Greenly, J. M., \& Tester, J. W. (2015). Ultrasonic cavitation for disruption of microalgae. Bioresource Technology, 184, 276-279.

Hardy, V., Thompson, M., Alto, W., Keppel, G. A., Hornecker, J., Linares, A., Robitaille, B., \& Baldwin, L. M. (2016). Exploring the barriers and facilitators to use of point of care tests in family medicine clinics in the United States. BMC Family Practice, 17(1), 149.

Hou, Y., Meulia, T., Gao, X., Saif, L. J., \& Wang, Q. (2019). Deletion of both the tyrosine-based endocytosis signal and the endoplasmic reticulum retrieval signal in the cytoplasmic tail of spike protein attenuates porcine epidemic diarrhea virus in pigs. Journal of Virology, 93, 43.

Hu, J., Wang, S., Wang, L., Li, F., Pingguan-Murphy, B., Lu, T. J., \& Xu, F. (2014). Advances in paper-based point of-care diagnostics. Biosensors and Bioelectronics, 15, 585-597.

Huckle, D. (2015). The impact of new trends in POCTs for companion diagnostics, non-invasive testing and molecular diagnostics. Expert Review of Molecular Diagnostics, 15(6), 815-827.

Kao, C. F., Chiou, H. Y., Chang, Y. C., Hsueh, C. S., Jeng, C. R., Tsai, P. S., Cheng, I. C., Pang, V. F., \& Chang, H. W. (2018). The characterization of immunoprotection induced by a cDNA clone derived from the attenuated taiwan porcine epidemic diarrhea virus pintung 52 strain. Viruses, 10(10), 543.

Liu, S., Su, W., \& Ding, X. (2016). A review on microfluidic paper-based analytical devices for glucose detection. Sensors (Basel), 16(12), 2086.
Masiuk, D. M., Sosnztskyi, O. I., Kokariev, A. V., \& Vasilenko, T. O. (2018). Evaluation of the cleansing and disinfection protocol of pig-breeding premises contaminated by the porcine epidemic diarrhea virus. Scientific Messenger of Lviv National University of Veterinary Medicine and Biotechnologies, 20(92), 130-136.

Merkle, S. K., \& Kleeberg, J. (2015). Fritsche recent developments and applications of solid phase microextraction (SPME) in food and environmental analysis - a review. Chromatography, 2, 293-381.

Perry, M. D., White, P. L., \& Barnes, R. A. (2014). Comparison of four automated nucleic acid extraction platforms for the recovery of DNA from Aspergillus fumigatus. Journal of Medical Microbiology, 63(9), 1160-1166.

Schrader, C., Schielke, A., Ellerbroek, L., \& Johne, R. (2012), PCR inhibitors occurrence, properties and removal. Journal of Applied Microbiology, 113, $1014-1026$.

Siegel, C. S., Stevenson, F. O., \& Zimmer, E. A. (2017). Evaluation and comparison of FTA card and CTAB DNA extraction methods for non-agricultural taxa. Applications in Plant Sciences, 5(2), 15.

Sun, J., Li, Q., Shao, C., Ma, Y., He, H., Jiang, S., Zhou, Y., Wu, Y., Ba, S., Shi, L., Fang, W., Wang, X., \& Song, H. (2018). Isolation and characterization of Chinese porcine epidemic diarrhea virus with novel mutations and deletions in the S gene. Veterinary Microbiology, 221, 81-89.

Thatcher, S. A. (2015). DNA/RNA preparation for molecular detection. Clinical Chemistry, 61(1), 89-99.

Tun, H. M., Cai, Z., \& Khafipour, E. (2016). Monitoring survivability and infectivity of porcine epidemic diarrhea virus (PEDv) in the infected onfarm earthen manure storages (EMS). Frontiers in Microbiology, 9(7), 265.

Wang, S., Lifson, M. A., Inci, F., Liang, L. G., Sheng, Y. F., \& Demirci, U. (2016). Advances in addressing technical challenges of point-of-care diagnostics in resource-limited settings. Expert Review of Molecular Diagnostics, 16(4), 449-459.

Wanitchang, A., Saenboonrueng, J., Kaewborisuth, C., Srisutthisamphan, K., \& Jongkaewwattana, A. (2019). A single V672F substitution in the spike protein of field-isolated PEDV promotes cell-cell fusion and replication in veroE6 cells. Viruses, 11, 282.

Yamada, K., Shibata, H., Suzuki, K., \& Citterio, D. (2017). Toward practical application of paper-based microfluidics for medical diagnostics: State-ofthe-art and challenges. Lab on a Chip, 17(7), 1206-1249.

Yonghyan, K., Yang, M., Goyal, S. M., Cheeran, M. C.-J., \& Torremorell, M. (2017). Evaluation of biosecurity measures to prevent indirect transmission of porcine epidemic diarrhea virus. BMC Veterinary Research, 13(89), 9.

Yuan, L., Zhang, S., Peng, J., Li, Y., \& Yang, Q. (2019) Synthetic surfactin analogues have improved anti-PEDV properties. PLoS One, 14(4), 14.

Zhou, Y., Chen, C., Chen, Y., Liu, Z., Zheng, J., Wang, T., Luo, H., Liu, Y., Shan, Y., Fang, W., \& Li, X. (2019). Effect of route of inoculation on innate and adaptive immune responses to porcine epidemic diarrhea virus infection in suckling pigs. Veterinary Microbiology, 228, 83-92. 